\title{
One Anastomosis/Mini-Gastric Bypass (OAGB/MGB) as Revisional Surgery Following Primary Restrictive Bariatric Procedures: a Systematic Review and Meta-Analysis
}

\author{
Mohammad Kermansaravi ${ }^{1}$ - Shahab Shahabi Shahmiri ${ }^{2}$ - Amir Hossein DavarpanahJazi ${ }^{2} \cdot$ Rohollah Valizadeh $^{3}$. \\ Giovanna Berardi ${ }^{4} \cdot$ Antonio Vitiello $^{4} \cdot$ Mario Musella $^{4}$ (D) Miguel Carbajo $^{5}$
}

Received: 18 August 2020 / Revised: 19 October 2020 / Accepted: 21 October 2020 / Published online: 28 October 2020

(C) The Author(s) 2020

\begin{abstract}
One anastomosis gastric bypass (OAGB/MGB) has gained popularity in the past decade. International databases were searched for articles published by September 10, 2020, on OAGB/MGB as a revisional procedure after restrictive procedures. Twenty-six studies examining a total of 1771 patients were included. The mean initial BMI was $45.70 \mathrm{~kg} / \mathrm{m}^{2}$, which decreased to 31.52 , 31.40 , and $30.54 \mathrm{~kg} / \mathrm{m}^{2}$ at 1,3 , and 5 -year follow-ups, respectively. Remission of type-2 diabetes mellitus (T2DM) following OAGB/MGB at 1-, 3-, and 5-year follow-up was 65.16 $\pm 24.43,65.37 \pm 36.07$, and 78.10 $\pm 14.19 \%$, respectively. Remission/ improvement rate from gastroesophageal reflux disease (GERD). Also, 7.4\% of the patients developed de novo GERD following OAGB/MGB. Leakage was the most common major complication. OAGB/MGB appears to be feasible and effective as a revisional procedure after failed restrictive bariatric procedures.
\end{abstract}

Keywords One anastomosis gastric bypass $(\mathrm{OAGB} / \mathrm{MGB}) \cdot$ Gastric bypass $\cdot$ Weight regain $\cdot$ Weight loss $\cdot$ Conversion

\section{Introduction}

In last years, bariatric surgery has proven to be the most effective treatment for morbid obesity and obesity-related

Supplementary Information The online version contains supplementary material available at https://doi.org/10.1007/s11695-02005079-x.

Mario Musella

mario.musella@unina.it

1 Department of Surgery, Minimally Invasive Surgery Research Center, Division of Minimally Invasive and Bariatric Surgery, Rasool-e Akram Hospital, Iran University of Medical Sciences, Tehran, Iran

2 Minimally Invasive Surgery Research Center, Isfahan University of Medical Sciences, Isfahan, Iran

3 Department of Epidemiology, Student Research Committee, School of Public Health, Iran University of Medical science, Tehran, Iran

4 Advanced Biomedical Sciences Department, "Federico II" University, Naples, Italy

5 Centre of Excellence for the Study and Treatment of Obesity and Diabetes, Valladolid, Spain diseases, providing long-standing effects and presenting a very low complication rate [1-3]. One anastomosis gastric bypass was firstly introduced by Rutledge as mini-gastric bypass (MGB) in 2001 [4] and subsequently modified as OAGB by Carbajo in 2005 [5]. It is currently an accepted bariatric procedure named as OAGB/MGB by IFSO [6], which has gained increasing popularity among bariatric surgeons worldwide [7]; efficacy and safety of primary OAGB/MGB have been reported in many different papers [8-12]. Due to the growing request for revisional bariatric surgery that recorded a steep increase in last years, rising from 6 to $13.6 \%$ of all bariatric procedures, a number of articles about conversional OAGB/MGB following primary restrictive procedures have been already published. Current revisional surgery rates are in fact reported to range from $9.8 \%$ for laparoscopic sleeve gastrectomy, to $26 \%$ for laparoscopic adjustable gastric banding [13]. Although a systematic review of the studies reporting results and complications of conversional OAGB/MGB has been very recently released [14], a study offering an analytic approach to conversional OAGB/MGB following laparoscopic adjustable gastric banding (LAGB), laparoscopic sleeve gastrectomy (LSG), and vertical banded gastroplasty (VBG) is still lacking. Aim of this study is therefore to define through 
a meta-analysis the role of OAGB/MGB as a conversional procedure after failed restrictive procedures, such as LAGB, LSG, and VBG.

\section{Methods}

A literature search was carried out based on the Preferred Reporting Items for Systematic Review and Meta-Analyses (PRISMA) guidelines [15] (see supplementary material). PubMed, Cochrane, and Scopus were consulted for articles published by September 10, 2020, on OAGB/MGB as a revisional procedure following restrictive procedures. The keywords searched were "One anastomosis gastric bypass," "OAGB," "Single-anastomosis gastric bypass," "Weight regain," "Weight loss," "Conversion," "Mini gastric bypass," "MGB," "Failure," "Redo," "Revisional surgery," "Conversional surgery," “omega loop gastric bypass," or "loop gastric bypass," "revisional bariatric surgery," "secondary bariatric surgery," "revisional sleeve gastrectomy," "band to bypass," "revision to bypass," or a combination of them in the titles or abstracts. The search strategy for can be found in the supplementary files. Two of the authors independently assessed the eligibility of the papers according to the PRISMA guidelines. The references of the articles were manually reviewed for additional relevant papers. The duplicate studies were removed.

\section{Statistical Analysis}

The effect of revisional surgery on body mass index (BMI) was assessed using the standardized mean difference (SMD), also known as Cohen's D. The SMD was calculated by using the mean difference and standard deviations (SD) before and after the surgery based on the SMD formula $(\mathrm{SMD}=$ mean difference in the intervention group - mean difference in the placebo group/pooled SD), and the pooled SD was calculated as $\sqrt{ }$ [(SD in the intervention group) $2+(\mathrm{SD}$ in the placebo group) 2/2]. Q-test and $\mathrm{I}^{2}$ were used to assess the heterogeneity among the studies. The random-effects model was used for the continuous outcome under study. Also, a random or fixedeffects meta-analysis was applied for estimating the main index, which was the pooled SMD, at $95 \%$ confidence interval. A forest plot was used to present the pooled SMD. Publication bias was assessed using Begg's tests. The analysis was performed using Stats version 13.

\section{Data Extraction}

Data on the included articles (author's name, year of publication, interval to revision, sample size, type of primary surgery, and the outcomes and results of each article) were retrieved by two independent investigators. The differences observed in this process were corrected by a third investigator independent from the other two.

The quality of the selected studies was checked by a quality assessment tool for before-after (pre-post) studies with no control groups [16].

\section{Results}

A total of 26 studies [8, 9, 17-40] examining 1771 patients were included in this meta-analysis (Fig. 1). Since the results of OAGB/MGB were classified and used as a revisional procedure in view of a primary procedure, some articles are quoted in more than one table (Tables 1, 2, and 3).

\section{Weight Regain Definition}

The definitions provided for weight regain in the studies were different, but $33.3 \%$ of the studies relied on $\mathrm{BMI} \geq 35$ or EWL $\leq 50 \%$. Also, EBMIL $<50 \%$ and EBMIL $\leq 25 \%$ were used for defining weight regain in $28.6 \%$ of the studies included in this review (Table 4).

\section{Conversional OAGB/MGB Etiologies}

Weight regain and weight loss failure were the most frequent causes of revisional OAGB/MGB. Weight loss failure was reported as the most common etiology for revisional procedure. Other causes included abdominal pain/dyspepsia, port infection, device-related complications, or intolerance to restriction, such as band migration, slippage and port infection, recurrence of type-2 diabetes mellitus, gastroesophageal reflux disease (GERD), dysphagia, and esophageal disorders (Fig. 2).

\section{Biliopancreatic Limb Length}

This review showed that the most common biliopancreatic limb length in OAGB/MGB was $200 \mathrm{~cm}$ (36\% of the studies). The biliopancreatic limb length varied from 150 to $350 \mathrm{~cm}$ (Table 5).

\section{Weight Loss Outcomes at 1-, 3-, and 5-Year Follow- Ups}

The mean initial BMI was $45.70 \mathrm{~kg} / \mathrm{m}^{2}$, which decreased to 31.5 , 31.4 , and $30.5 \mathrm{~kg} / \mathrm{m}^{2}$ at 1-, 3-, and 5-year follow-ups, respectively (Table 6). The forest plots depict the effects of OAGB/MGB on BMI after 1, 3, and 5 years (Figs. 2, 3, 4, and 5).

A random effect model was also used to measure the effect of the standardized mean difference (SMD). Based on the results of the included studies, OAGB/MBG has been effective in accomplishing weight loss. Nonetheless, at 1-, 3-, and 5-year follow-ups, BMI decreased by an SMD of $-1.8,-2.1$, and 1.5 , showing the acceptable and durable effects of OAGB/MGB. 
Table 1 Study characteristics with primary surgery of LSG included in meta-analysis

\begin{tabular}{|c|c|c|c|c|c|c|c|c|c|c|c|c|c|c|c|c|}
\hline \multirow[t]{3}{*}{ Author } & \multirow{3}{*}{$\begin{array}{l}\text { Type of } \\
\text { primary } \\
\text { surgery }\end{array}$} & \multirow{3}{*}{$\begin{array}{l}\text { Number } \\
\text { of patients }\end{array}$} & \multirow{3}{*}{$\begin{array}{l}\text { Interval to } \\
\text { revision } \\
\text { (month) }\end{array}$} & \multicolumn{6}{|c|}{ Pre-revision BMI $\left(\mathrm{kg} / \mathrm{m}^{2}\right)$} & \multicolumn{6}{|c|}{ Post-revision BMI $\left(\mathrm{kg} / \mathrm{m}^{2}\right)$} & \multirow{3}{*}{$\begin{array}{l}\text { Mean } \\
\text { follow-up } \\
\text { (year) }\end{array}$} \\
\hline & & & & \multicolumn{2}{|c|}{ At primary } & \multicolumn{2}{|l|}{ Nadir } & \multicolumn{2}{|c|}{$\begin{array}{l}\text { At } \\
\text { revision }\end{array}$} & \multicolumn{2}{|l|}{1 year } & \multicolumn{2}{|c|}{$\leq 3$ years } & \multicolumn{2}{|c|}{$\leq 5$ years } & \\
\hline & & & & Mean & SD & Mean & $\mathrm{SD}$ & Mean & $\mathrm{SD}$ & Mean & SD & Mean & SD & Mean & SD & \\
\hline $\begin{array}{l}\text { Poublon } \\
2020[31]\end{array}$ & LSG & 65 & - & 45.7 & - & 40.9 & - & - & - & 30.7 & - & 31.1 & 5.1 & - & - & NA \\
\hline $\begin{array}{l}\text { Chevallier } \\
\text { et al., } \\
2015 \text { [8] }\end{array}$ & LSG & NA & - & - & - & - & - & 44.5 & 6.4 & - & - & 28.9 & 3.7 & - & - & 2.5 \\
\hline $\begin{array}{l}\text { Lessing et al., } \\
2017 \text { [32] }\end{array}$ & LSG & 27 & 105.6 & - & - & - & - & 42.2 & 8.3 & - & - & - & - & - & - & 4 \\
\hline $\begin{array}{l}\text { Mora Oliver } \\
\text { et al., } 2019 \\
\text { [33] }\end{array}$ & LSG & 26 & 70 & - & - & - & - & - & - & - & - & - & - & - & - & 1.6 \\
\hline $\begin{array}{r}\text { Bruzzi et al., } \\
2016 \text { [24] }\end{array}$ & LSG & NA & 34 & - & - & - & - & 45.5 & 7 & 33 & 4.5 & 30.5 & 4 & 32 & 5 & $5.5^{*}$ \\
\hline $\begin{array}{c}\text { AlSabah et al., } \\
2018 \text { [22] }\end{array}$ & LSG & 31 & 61 & 49 & & 32.2 & - & 42.6 & & 32.2 & 5.1 & - & - & - & - & NA \\
\hline $\begin{array}{c}\text { Bhandari et al., } \\
2019 \text { [23] }\end{array}$ & LSG & 32 & - & 44.04 & & 34.22 & - & 38.53 & & 34.33 & & 37.14 & & - & - & NA \\
\hline $\begin{array}{l}\text { Moszkowicz } \\
\text { et al., } \\
2013 \text { [18] }\end{array}$ & LSG & 21 & 26.3 & 50.6 & 12.3 & - & - & 44 & 7.7 & 34.6 & 5.2 & 35.7 & 4.3 & & & 1.4 \\
\hline $\begin{array}{l}\text { Poghosyan } \\
\text { et al., } \\
2019 \text { [27] }\end{array}$ & LSG & 72 & 28 & 49.1 & 8 & - & - & 43.6 & 7 & 34.6 & 5 & 33 & 9 & 34.7 & 9 & NA \\
\hline $\begin{array}{l}\text { Debs et al., } \\
2020[26]\end{array}$ & LSG & 77 & 53.7 & 46.9 & & - & - & 40.1 & & 29.8 & & - & - & 29.1 & 5 & 4.5 \\
\hline $\begin{array}{r}\text { Jamal et al., } \\
2020[30]\end{array}$ & LSG & 56 & - & & & - & - & 41.9 & 7.9 & 30.5 & 9.4 & - & - & - & - & 1.5 \\
\hline $\begin{array}{l}\text { Chiappetta } \\
2019[25]\end{array}$ & LSG & 34 & 38.5 & 56.5 & 8.8 & - & - & 45.7 & 8 & 36.6 & 6.3 & - & - & - & - & NA \\
\hline $\begin{array}{l}\text { Musella et al., } \\
2019 \text { [19] }\end{array}$ & LSG & 104 & 21.8 & 41.25 & 8.34 & - & - & 41.8 & 6.3 & - & - & 30.5 & 5.5 & - & - & 1.7 \\
\hline $\begin{array}{l}\text { Lessing et al., } \\
\quad 2020 \text { [17] }\end{array}$ & LSG & 4 & 142.8 & 46.7 & 5.9 & - & - & 42.8 & 7 & 31.3 & 5.2 & - & - & - & - & $\begin{array}{c}\text { 1-year: } \\
\text { 100\% } \\
\text { 2-year: } \\
71.9 \%\end{array}$ \\
\hline $\begin{array}{l}\text { Noun et al., } \\
2018 \text { [29] }\end{array}$ & LSG & 7 & - & 45 & 4.8 & 35 & 5 & 42.9 & 6.5 & 28.5 & 4 & - & - & - & - & NA \\
\hline
\end{tabular}

*Estimated mean using median and interquartile range (available at http://www.math.hkbu.edu.hk/ tongt/papers/median2mean.html)

At the 1-year follow-up, OAGB/MGB following LAGB was most effective in decreasing BMI, with an SMD of -2.01 . Also, OAGB/MGB following LSG $(\mathrm{SMD}=-1.7)$ showed a better effectiveness compared to VBG $(\mathrm{SMD}=-1.3)$. In the 3year follow-up, OAGB/MGB after LAGB was most effective in decreasing BMI with an SMD of -2.1. In the 5-year follow-up, OAGB/MGB following LAGB was most effective in decreasing BMI, with an SMD of -1.7. In this follow-up, conversional OAGB/MGB after VBG (SMD = - 1.4) played an effective role in BMI reduction. The effect of OABG on BMI after a 1-year follow-up with the presence of remnant resection showed no significant difference between the two states (Table 11).

\section{Comorbidity and Remission}

The comorbidities included in this meta-analysis were T2DM [3], hypertension (HTN), obstructive sleep apnea (OSA), and dyslipidemia (DL) (Tables 7 and 8).

\section{Diabetes Outcomes}

Remission of T2DM following OAGB/MGB surgery at 1-, 3-, and 5-year follow-up was 65.2 $\pm 24.4,65.4 \pm 36.1$, and 78.1 \pm 14.2 , respectively. The remission range of T2DM at the 1-, 3-, 
Table 2 Study characteristics with primary surgery of LABG included in meta-analysis

\begin{tabular}{|c|c|c|c|c|c|c|c|c|c|c|c|c|c|c|c|c|}
\hline \multirow[t]{3}{*}{ Author } & \multirow{3}{*}{$\begin{array}{l}\text { Type of } \\
\text { primary } \\
\text { surgery }\end{array}$} & \multirow{3}{*}{$\begin{array}{l}\text { Number } \\
\text { of } \\
\text { patients }\end{array}$} & \multirow{3}{*}{$\begin{array}{l}\text { Interval to } \\
\text { revision } \\
\text { (month) }\end{array}$} & \multicolumn{6}{|c|}{ Pre-revision BMI $\left(\mathrm{kg} / \mathrm{m}^{2}\right)$} & \multicolumn{6}{|c|}{ Post-revision BMI $\left(\mathrm{kg} / \mathrm{m}^{2}\right)$} & \multirow{3}{*}{$\begin{array}{l}\text { Mean } \\
\text { follow-up } \\
\text { (year) }\end{array}$} \\
\hline & & & & \multicolumn{2}{|c|}{ At primary } & \multicolumn{2}{|l|}{ Nadir } & \multicolumn{2}{|c|}{ At revision } & \multicolumn{2}{|l|}{1 year } & \multicolumn{2}{|c|}{$\leq 3$ years } & \multicolumn{2}{|c|}{$\leq 5$ years } & \\
\hline & & & & Mean & SD & Mean & $\mathrm{SD}$ & Mean & $\mathrm{SD}$ & Mean & $\mathrm{SD}$ & Mean & $\mathrm{SD}$ & Mean & $\mathrm{SD}$ & \\
\hline $\begin{array}{l}\text { Noun et al., } \\
2018 \text { [29] }\end{array}$ & LAGB & 10 & - & 45 & 4.8 & 35 & 5 & 42.9 & 6.5 & 28.5 & 4 & - & - & - & - & NA \\
\hline $\begin{array}{l}\text { Noun et al., } \\
2012 \text { [40] }\end{array}$ & LAGB & 77 & - & 41.25 & 8.34 & - & - & - & - & - & - & - & - & - & - & $\begin{array}{c}\text { 1-year: } \\
83.6 \% \\
\text { 1.5-year: } \\
83 \% \\
\text { 3-years: } \\
81 \% \\
\text { 4-years: } \\
78 \% \\
\text { 5-years: } 70\end{array}$ \\
\hline $\begin{array}{l}\text { Lessing et al., } \\
\quad 2020 \text { [17] }\end{array}$ & LAGB & 53 & 142.8 & 46.7 & 5.9 & - & - & 42.8 & 7 & 31.3 & 5.2 & - & - & - & - & $\begin{array}{c}\text { 1-year: } \\
\text { 100\% } \\
\text { 2-year: } \\
71.9 \%\end{array}$ \\
\hline $\begin{array}{l}\text { Poublon } 2020 \\
\quad[31]\end{array}$ & LAGB & 120 & - & 45.7 & - & 40.9 & - & - & - & 30.7 & - & 31.1 & 5.1 & - & - & NA \\
\hline $\begin{array}{l}\text { Musella et al., } \\
2019 \text { [19] }\end{array}$ & LAGB & 196 & 21.8 & 41.25 & 8.34 & - & - & 41.8 & 6.3 & - & - & 30.5 & 5.5 & - & - & 1.7 \\
\hline $\begin{array}{l}\text { Piazza et al., } \\
2015 \text { [20] }\end{array}$ & LAGB & 47 & 28.5 & - & - & - & - & 43.4 & 4.2 & 34.1 & 3.77 & - & - & - & - & NA \\
\hline $\begin{array}{l}\text { Chevallier } \\
\text { et al., } \\
2015 \text { [8] }\end{array}$ & LAGB & 41 & - & - & - & - & - & 44.5 & 6.4 & - & - & 28.9 & 3.7 & - & - & 2.6 \\
\hline $\begin{array}{l}\text { Lessing et al., } \\
2017 \text { [32] }\end{array}$ & LAGB & 71 & 105.6 & - & - & - & - & 42.2 & 8.3 & - & - & - & - & - & - & 4 \\
\hline $\begin{array}{l}\text { Mora Oliver } \\
\quad \text { et al., } \\
2019 \text { [33] }\end{array}$ & LAGB & 26 & 70 & - & - & - & - & - & - & - & - & - & - & - & - & 1.7 \\
\hline $\begin{array}{l}\text { Chansaenroj } \\
\text { et al., } \\
2017 \text { [34] }\end{array}$ & LAGB & 26 & - & 39.9 & 10.5 & - & - & 39.3 & 8.9 & 27.4 & 5.2 & 26.8 & 4.8 & - & - & $\begin{array}{r}\text { 5-year: } \\
34.1 \% \\
\text { 10-years: } \\
30.6 \%\end{array}$ \\
\hline $\begin{array}{r}\text { Ghosh et al., } \\
2017 \text { [35] }\end{array}$ & LAGB & 74 & - & 48.9 & 11.2 & - & - & 46 & 8.9 & 33.2 & 7.34 & - & - & - & - & $\begin{array}{l}\text { 6-week: } \\
97 \% \\
\text { 3-months: } \\
85 \% \\
\text { 6-months: } \\
\text { 69\% } \\
\text { 1-year: } \\
46 \%\end{array}$ \\
\hline $\begin{array}{l}\text { Noun et al., } \\
2007[36]\end{array}$ & LAGB & 16 & 36.3 & & & - & - & 39.5 & 10.4 & 30.6 & 4.77 & - & - & - & - & 0.6 \\
\hline $\begin{array}{l}\text { Rutledge et al., } \\
2006 \text { [37] }\end{array}$ & LAGB & 3 & - & - & - & - & - & 38.7 & 7 & & & - & - & - & - & NA \\
\hline $\begin{array}{l}\text { Pujol Rafols } \\
\text { et al., } 2018 \\
\text { [28] }\end{array}$ & LAGB & 191 & - & 44.3 & 6.8 & - & - & 39.8 & 6.9 & - & - & - & - & 30.3 & 5.4 & 2.8 \\
\hline $\begin{array}{c}\text { Carbajo et al. } \\
2017 \text { [9] }\end{array}$ & LAGB & 13 & - & - & - & - & - & 41.6 & 5.6 & - & - & - & - & 28.5 & 5.2 & $\begin{array}{c}\text { 6-years: } \\
87 \% \\
\text { 12-years: } \\
70 \%\end{array}$ \\
\hline $\begin{array}{r}\text { Bruzzi et al., } \\
2016 \text { [24] }\end{array}$ & LAGB & 30 & 34 & - & - & - & - & 45.5 & 7 & 33 & 4.5 & 30.5 & 4 & 32 & 5 & 66.5 \\
\hline
\end{tabular}


Table 3 Study characteristics with primary surgery of VBG included in meta-analysis

\begin{tabular}{|c|c|c|c|c|c|c|c|c|c|c|c|c|c|c|c|c|}
\hline \multirow[t]{3}{*}{ Author } & \multirow{3}{*}{$\begin{array}{l}\text { Type of } \\
\text { primary } \\
\text { surgery }\end{array}$} & \multirow{3}{*}{$\begin{array}{l}\text { Number } \\
\text { of patients }\end{array}$} & \multirow{3}{*}{$\begin{array}{l}\text { Interval to } \\
\text { revision } \\
\text { (month) }\end{array}$} & \multicolumn{6}{|c|}{ Pre-revision BMI $\left(\mathrm{kg} / \mathrm{m}^{2}\right)$} & \multicolumn{6}{|c|}{ Post-revision BMI $\left(\mathrm{kg} / \mathrm{m}^{2}\right)$} & \multirow{3}{*}{$\begin{array}{l}\text { Mean } \\
\text { follow-up } \\
\text { (year) }\end{array}$} \\
\hline & & & & \multicolumn{2}{|c|}{$\begin{array}{l}\text { At } \\
\text { primary }\end{array}$} & \multicolumn{2}{|l|}{ Nadir } & \multicolumn{2}{|c|}{ At revision } & \multicolumn{2}{|l|}{1 year } & \multicolumn{2}{|c|}{$\leq 3$ years } & \multicolumn{2}{|c|}{$\leq 5$ years } & \\
\hline & & & & Mean & SD & Mean & SD & Mean & $\mathrm{SD}$ & Mean & SD & Mean & $\mathrm{SD}$ & Mean & $\mathrm{SD}$ & \\
\hline $\begin{array}{c}\text { Carbajo et al. } \\
2017 \text { [9] }\end{array}$ & VBG & 14 & - & - & - & - & - & 41.6 & 5.6 & - & - & - & - & 28.5 & 5.2 & 7.5 \\
\hline $\begin{array}{l}\text { Chevallier } \\
\text { et al., } \\
2015 \text { [8] }\end{array}$ & VBG & NA & - & - & - & - & - & 44.5 & 6.4 & - & - & 28.9 & 3.7 & - & - & 2.6 \\
\hline $\begin{array}{r}\text { Bruzzi et al., } \\
2016 \text { [24] }\end{array}$ & VBG & 30 & 34 & - & - & - & - & 45.5 & 7 & 33 & 4.5 & 30.5 & 4 & 32 & 5 & 5.8 \\
\hline $\begin{array}{l}\text { Mora Oliver } \\
\text { et al.,2019 } \\
{[33]}\end{array}$ & VBG & 36 & 70 & - & - & - & - & - & - & - & - & - & - & - & - & 1.7 \\
\hline $\begin{array}{l}\text { Noun et al., } \\
2007 \text { [36] }\end{array}$ & VBG & 17 & 36.3 & & & - & - & 39.5 & 10.4 & 30.6 & 4.8 & - & - & - & - & 0.8 \\
\hline $\begin{array}{c}\text { Salama et al., } \\
2016 \text { [38] }\end{array}$ & VBG & 39 & - & - & - & - & - & 39.7 & 8.2 & 30.2 & 5.4 & - & - & - & - & NA \\
\hline $\begin{array}{l}\text { Wang et al., } \\
2004 \text { [39] }\end{array}$ & VBG & 29 & 58.5 & - & - & - & - & 41.7 & & 32.1 & & - & - & - & - & NA \\
\hline $\begin{array}{l}\text { Almalki et al., } \\
2018 \text { [21] }\end{array}$ & VBG & 81 & 58.8 & - & - & - & - & 37.8 & 9.6 & 27.2 & 6.2 & - & - & 27.8 & 6.7 & $\begin{array}{c}\text { 1-year: } 60 \% \\
\text { 5-years: } \\
37 \%\end{array}$ \\
\hline
\end{tabular}

and 5-year follow-ups was 40-88.8\%, 12-88.8\%, and 62$94 \%$, respectively (Table 8 ).

\section{HTN Outcomes}

Remission of HTN following OAGB/MGB surgery at 1-, 3-, and 5-year follow-ups was $68.4 \pm 27.1,49.9 \pm 25$, and $74.7 \pm$ $16.2 \%$, respectively. The remission range for HTN at 1-, 3-, and 5-year follow-ups was 42-100\%, 21-81.8\%, and 58-9\%, respectively (Table 8 ).

\section{Dyslipidemia Outcomes}

Remission of DL following OAGB/MGB surgery at 1-, 3-, and 5-year follow-ups was $61.5 \pm 0,45.8 \pm 49.2$, and $85.50 \pm$ 14.8 , respectively. The remission range for DL at 1-, 3-, and 5year follow-ups was $61-61.5 \%, 11-80.6 \%$, and $75-96 \%$, respectively (Table 8 ).

\section{OSA Outcomes}

Remission of OSA following OAGB/MGB surgery at 1-, 3-, and 5-year follow-ups was $80.00 \pm 0,60.00 \pm 14.1$, and 86.00 \pm 5.7 , respectively. The remission range for OSA at 1-, 3-, and 5-year follow-ups was $80-80 \%, 50-70 \%$, and $82-90 \%$, respectively (Table 8).

\section{GERD Outcomes}

GERD following OABG surgery was also investigated. The results showed that $81.7 \%$ of the patients with GERD improved or had remission following OAGB/MGB (Table 9).

The results showed that $7.4 \%$ of the patients developed de novo GERD following OABG.

\section{Major Complications}

The major complications reported in the studies were extracted, and leakage proved to be the most common problem after revisional OAGB/MGB (0.016). The other complications included hematoma and abscess, GIB, reoperation, strangulated hernia at the trocar port, late incisional hernia, colonic necrosis, bowel obstruction, respiratory failure, anastomotic stricture, hypoalbuminemia, intractable bile reflux, small bowel ileus, pneumonia, GJ stoma fistula, hematemesis, port site infection, and ulceration (Table 10).

\section{Publication Bias}

The results of the analysis also showed that bias publication did not have an influence on the creation of negative results, which is shown as symmetry in the funnel plot. Meanwhile, no evidence of publication bias was detected using Egger's test (Egger's test $t=-2.03, P=0.06,95 \% \mathrm{CI}-3.4$ to 0.08 ). 


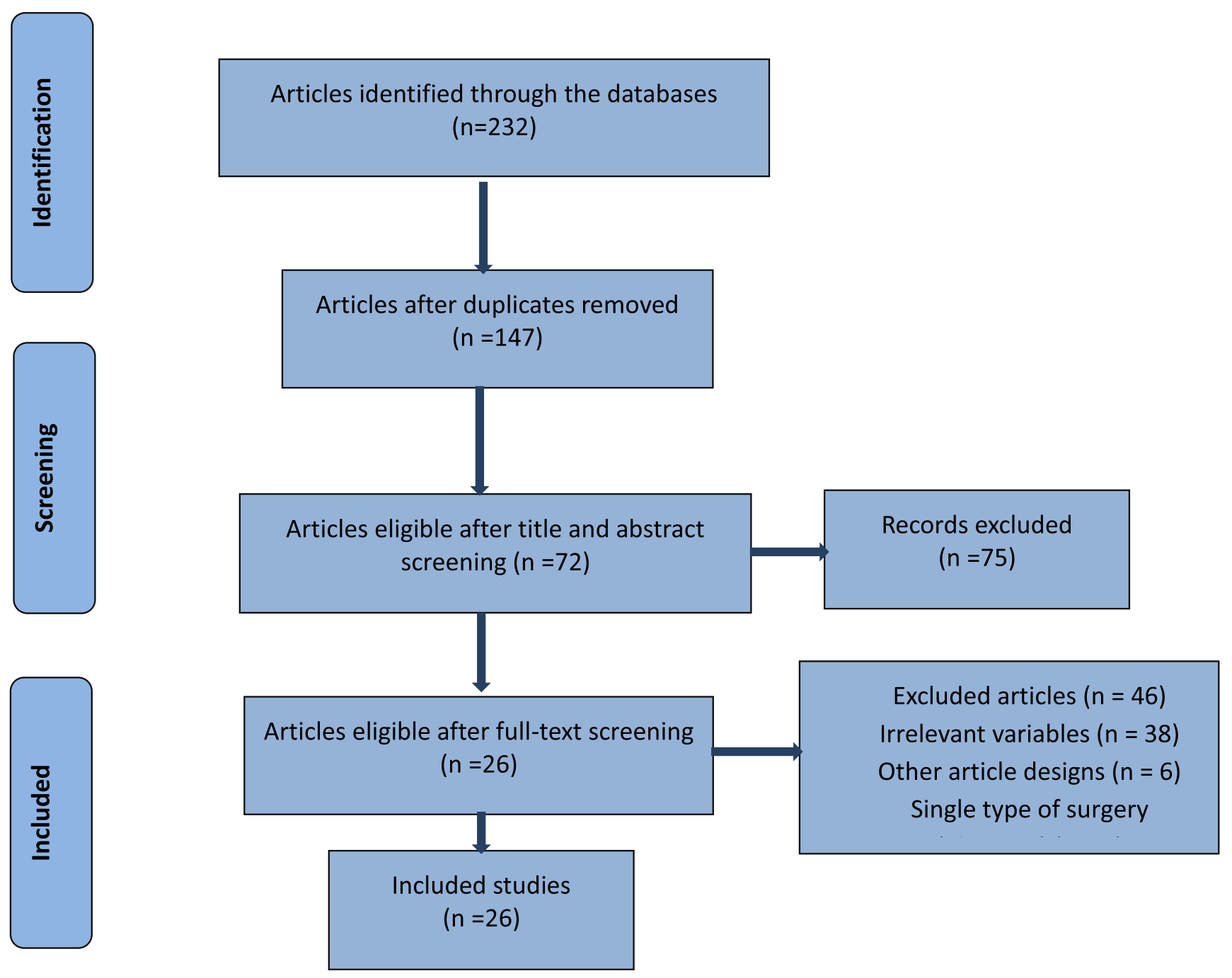

Fig. 1 Preferred Reporting Items for Systematic Reviews and Meta-Analyses (PRISMA)

\section{Discussion}

As reported in previously published studies [41, 42], weight loss failure and weight regain may occur in the long term following restrictive procedures. This review study revealed unsuccessful weight loss as the main reason for conversion to OAGB/MGB. All the 57 patients reported by Lessing et al. were converted to $\mathrm{OAGB} / \mathrm{MGB}$ due to weight regain after
Table 4 Type of weight regain definition used in included studies

\begin{tabular}{lll}
\hline Weight regain definition & Frequency & Rate \% \\
\hline BMI $\geq 35$ or EWL $\leq 50 \%$ & 7 & 33.3 \\
BMI $\geq 35$ & 2 & 9.5 \\
EWL 2 years $<50 \%$ or $>25 \%$ EWL regain compared with minimal weight & 1 & 4.8 \\
EWL 2 years $<50 \%$ & 1 & 4.8 \\
EBMIL $<50 \%$ & 3 & 14.3 \\
EBMIL $\leq 25 \%$ & 3 & 14.3 \\
EWL $<50 \% 18$ months after surgery & 1 & 4.8 \\
EWL $<50 \%$ at 18 -month follow-up and EWL $<30 \%$ at any time & 1 & 4.8 \\
EWL $<50 \%$, and BMI $\geq 50$ & 1 & 4.8 \\
EWL $<50 \%$ and/or TWL $<25 \%$ and/or BMI $>40$ at 2 years follow-up & 1 & 4.8
\end{tabular}




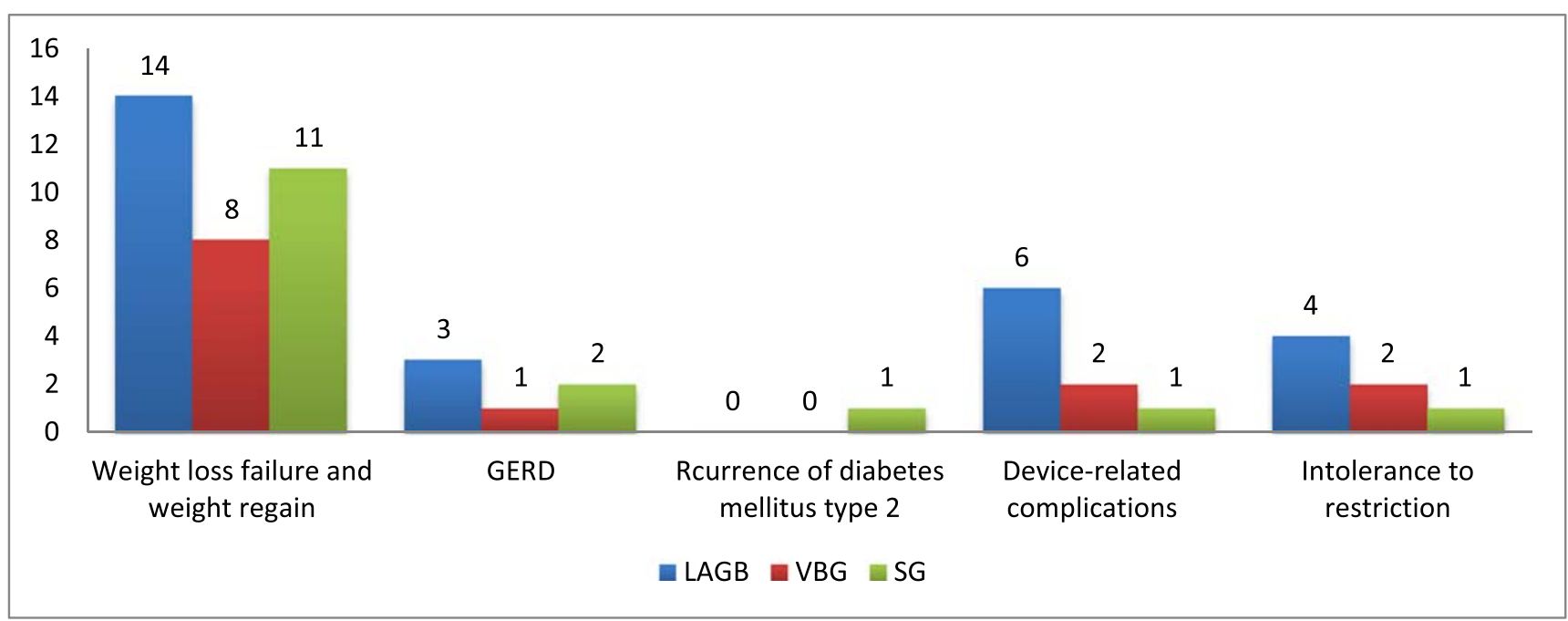

Fig. 2 Frequency of reported etiologies for revisional OAGB/MGB in included studies

gastric banding either by the 1-stage or 2-stage approach [17]. Also, all the reported revisional OAGB/MGBs in Moszkowicz' series were due to weight regain [18]. In the study by Musella et al., $77 \%$ of the restrictive operations (sleeve gastrectomy or banding) were converted due to weight loss failure, and only $23 \%$ of the revisions were due to surgical complications (dysphagia, disconnection of tube from the port, port infection and slippage, deterioration of preoperative gastroesophageal reflux (GERD), or de novo GERD) [19]. Band-related complications (slippage, migration, pouch dilation) (43\%), esophageal disorders (31\%), weight loss failure/ persistence of comorbidities (15\%), and food intolerance/ patient request $(11 \%)$ were the indications for revisional $\mathrm{OAGB} / \mathrm{MGB}$ in the other retrieved papers [20].

While insufficient weight loss was the principal reason for conversion, BPL length was found to represent a crucial technical point regarding revisional surgery. Nonetheless, in this review study, BPL varied from 150 to $350 \mathrm{~cm}$, as the optimal limb length in primary and revisional OAGB/MGB is still a matter for debate. The results of this research showed that the most common BPL length in OAGB/MGB was $200 \mathrm{~cm}$ (36\% of the studies). Meanwhile, some studies used 150-cm BPL lengths (and increased them by $10 \mathrm{~cm}$ for each BMI point above 40) [9, 21-26, 43, 44]. Poghosyan et al. found that weight loss and its outcomes are comparable between the 150-cm and 200-cm BPL [27]. Tovar et al. found that the ideal range was established between 0.40 and 0.43 for the CL/TBL ratio, and 200 and $220 \mathrm{~cm}$ for the CL length. Among these ranges, there were no cases of protein or calorie malnutrition [45]; therefore, it is better to measure the entire small intestine and use a maximum one-third of it for GJ to prevent malnutrition.
Table 5 Biliopancreatic limb length used in OAGB/MGB surgeries in included studies

\begin{tabular}{lll}
\hline Biliopancreatic limb length & Frequency & Rate \% \\
\hline $200 \mathrm{~cm}$ & 9 & 36 \\
$180-200 \mathrm{~cm}$ & 1 & 4 \\
$180-240 \mathrm{~cm}$ & 1 & 4 \\
$150 \mathrm{~cm}$ and $200 \mathrm{~cm}$ & 2 & 8 \\
$180 \mathrm{~cm}$ & 2 & 8 \\
$150-200 \mathrm{~cm}$ & 1 & 4 \\
$175-200 \mathrm{~cm}$ & 1 & 4 \\
$250 \mathrm{~cm}$ & 1 & 4 \\
$150 \mathrm{~cm}$ & 2 & 8 \\
$175 \mathrm{~cm}$ & 1 & 4 \\
$150 \mathrm{~cm}$ (and increased by $10 \mathrm{~cm}$ for each BMI point above 40$)$ & 1 & 4 \\
$150-250 \mathrm{~cm}$ & 1 & 4 \\
$150-300 \mathrm{~cm}$ & 1 & 4 \\
$250-350 \mathrm{~cm}$ tailored & 1 & 4 \\
\hline
\end{tabular}


Table 6 Mean and standard deviation of reported BMI at revision time and follow-up

\begin{tabular}{lll}
\hline Variable & Number of patients & Mean \pm Std. deviation \\
\hline At revision BMI $\left(\mathrm{kg} / \mathrm{m}^{2}\right)$ & 1584 & $42.3 \pm 2.2$ \\
Post-revision BMI $\leq 1$ year $\left(\mathrm{kg} / \mathrm{m}^{2}\right)$ & 761 & $31.6 \pm 2.5$ \\
Post-revision BMI $\leq 3$ years $\left(\mathrm{kg} / \mathrm{m}^{2}\right)$ & 658 & $31.4 \pm 3.1$ \\
Post-revision BMI $\leq 5$ years $\left(\mathrm{kg} / \mathrm{m}^{2}\right)$ & 505 & $30.6 \pm 2.3$ \\
\hline
\end{tabular}

Even though further studies are needed to identify the optimal length for primary and revisional OAGB/MGB, the present research demonstrated that, regardless of BPL, conversion from restrictive interventions has resulted in satisfactory and durable outcomes in series with 5-year follow-ups [9, 21, 24, 26-28]. According to pre and post-revisional BMI
Study

ID

Laparoscopic adjustable gastric banding (LAGB)

Chansaenroj et al., 2017

Ghosh et al., 2017

Lessing et al., 2020

Noun et al., 2007

Lessing et al., 2020

Piazza et al., 2015

Noun et al., 2018

Bruzzi et al., 2015

Poublon et al. 2020

Subtotal $(\mathrm{I}$-squared $=68.1 \%, p=0.002$

.

Laparoscopic sleeve gastrectomy (LSG)

Chiappettaet al., 2019

Jamal et al., 2020

Moszkowicz et al., 2013

Poghosyan et al., 2019

Bruzzi et al., 2015

Noun et al., 2018

Poublon et al. 2020

Subtotal $(\mathrm{I}$-squared $=73.0 \%, p=0.001$ )

Vertical banded gastroplasty (VBG)

Noun et al., 2007

Bruzzi et al., 2015

Salama et al., 2016

Almalki et al., 2018

Subtotal $(\mathrm{I}$-squared $=0.0 \%, p=0.769$ )

Overall (I-squared $=72.0 \%, p=0.000$ )
$\operatorname{SMD}(95 \% \mathrm{Cl})$

$\%$

Weight
$-1.63(-2.26,-1.00) \quad 3.13$

$-1.57(-1.94,-1.20) \quad 8.92$

$-1.66(-2.72,-0.60) \quad 6.87$

$-1.10(-1.82,-0.38) \quad 2.05$

$-1.86(-2.30,-1.41) \quad 6.87$

$-2.33(-2.85,-1.81) \quad 5.78$

$-2.67(-3.90,-1.43) \quad 1.20$

$-2.12(-2.87,-1.38) \quad 2.65$

$-2.52(-2.86,-2.18) \quad 14.46$

$-2.01(-2.22,-1.80) \quad 51.93$

$-1.26(-1.79,-0.74) \quad 4.10$

$-1.31(-1.72,-0.90) \quad 6.75$

$-1.43(-2.11,-0.75) \quad 2.53$

$-1.48(-1.85,-1.11) \quad 8.67$

$-2.12(-3.96,-0.29) \quad 0.48$

$-2.67(-4.16,-1.17) \quad 0.84$

$-2.52(-2.98,-2.06) \quad 7.83$

$-1.71(-1.92,-1.51) \quad 31.20$

$-1.10(-1.85,-0.35) \quad 1.93$

$-2.12(-3.96,-0.29) \quad 0.48$

$-1.38(-1.87,-0.88) \quad 4.70$

$-1.31(-1.65,-0.97) \quad 9.76$

$-1.33(-1.59,-1.07) \quad 16.87$

$-1.80(-1.94,-1.67) \quad 100.00$

Fig. 3 Forest plot showing the effect of OAGB/MGB on BMI after 1-year follow-up 
Study

ID
$\%$

$\operatorname{SMD}(95 \% \mathrm{Cl}) \quad$ Weight

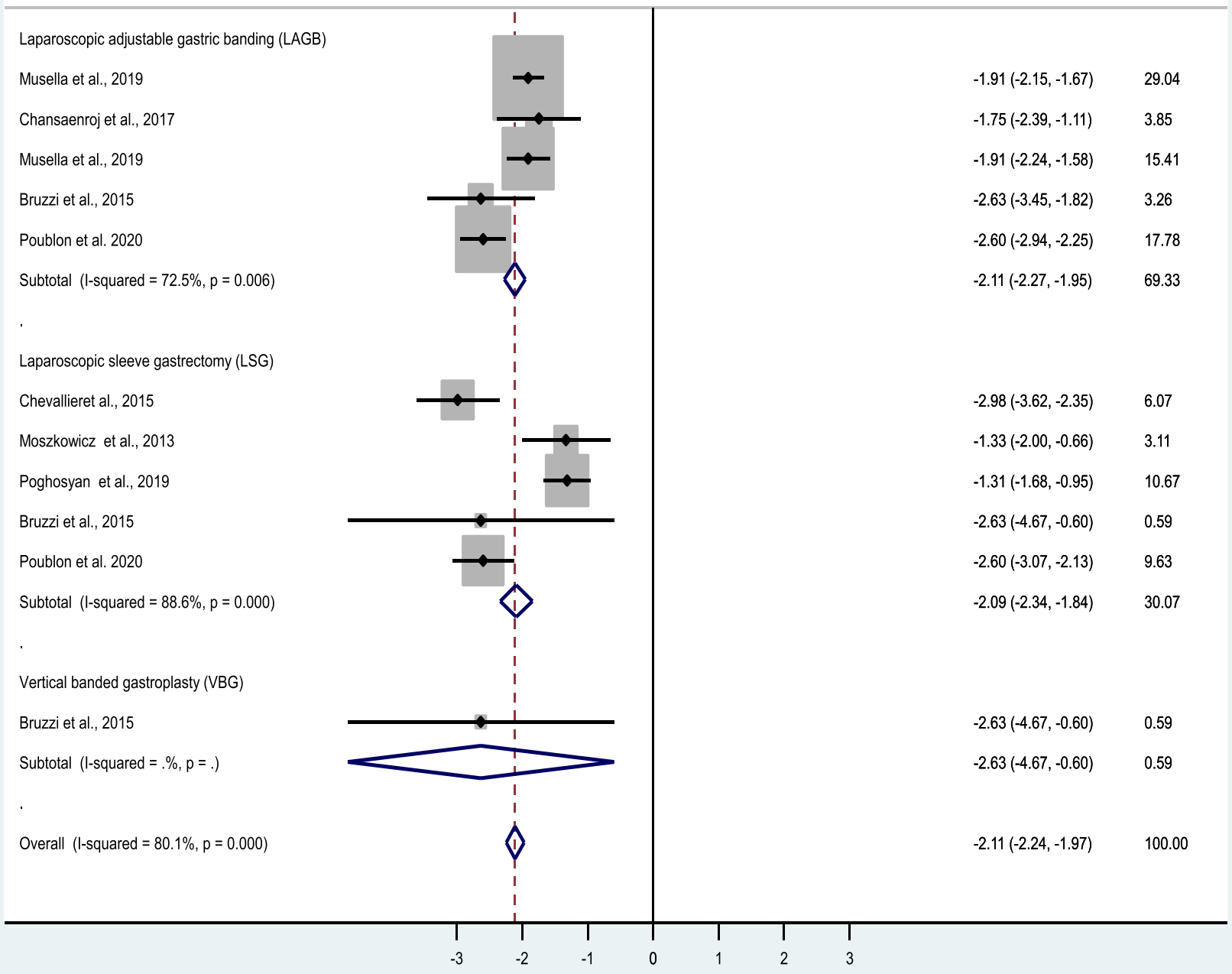

Fig. 4 Forest plot showing the effect of OAGB/MGB on BMI after 3-year follow-up

between groups, BMI loss was more significant after LAGB compared to OAGB/MGB following LSG or VBG, perhaps due to the lesser weight loss after LAGB as an initial bariatric surgical procedure in comparison with LSG and VBG. This finding may suggest that LAGB can have better postrevisional weight loss outcomes than LSG before gastric bypass [41]. This review of literature also showed that simultaneous gastric remnant resection, which was performed in some of the studies [21, 23, 25, 26, 29], has no significant effects on weight loss, but, in our opinion, it can only increase the risk for postoperative complications and hamper reversal surgery (Table 11).
Regarding the effects of conversion on T2DM, the present data demonstrated a range of remission up to $65-78 \%$ during the first 5 years. In Bruzzi's series, the remission rate for diabetic patients after revisional OAGB/MGB was $85 \%$ [24], while another study showed a $100 \%$ remission of T2DM after revisional OAGB/MGB compared to $60 \%$ remission after revisional RYGB [25]. Debs et al. also reported that ten out of 13 patients had remission or improvement of T2DM after revisional OAGB/MGB [26]. Musella et al. reported a $75 \%$ and $50 \%$ remission of T2DM after failed primary sleeve gastrectomy and adjustable banding, respectively, as restrictive operations converted to OAGB/MGB [19]. 
· Study

$\operatorname{SMD}(95 \% \mathrm{Cl}) \quad$ Weight

ID

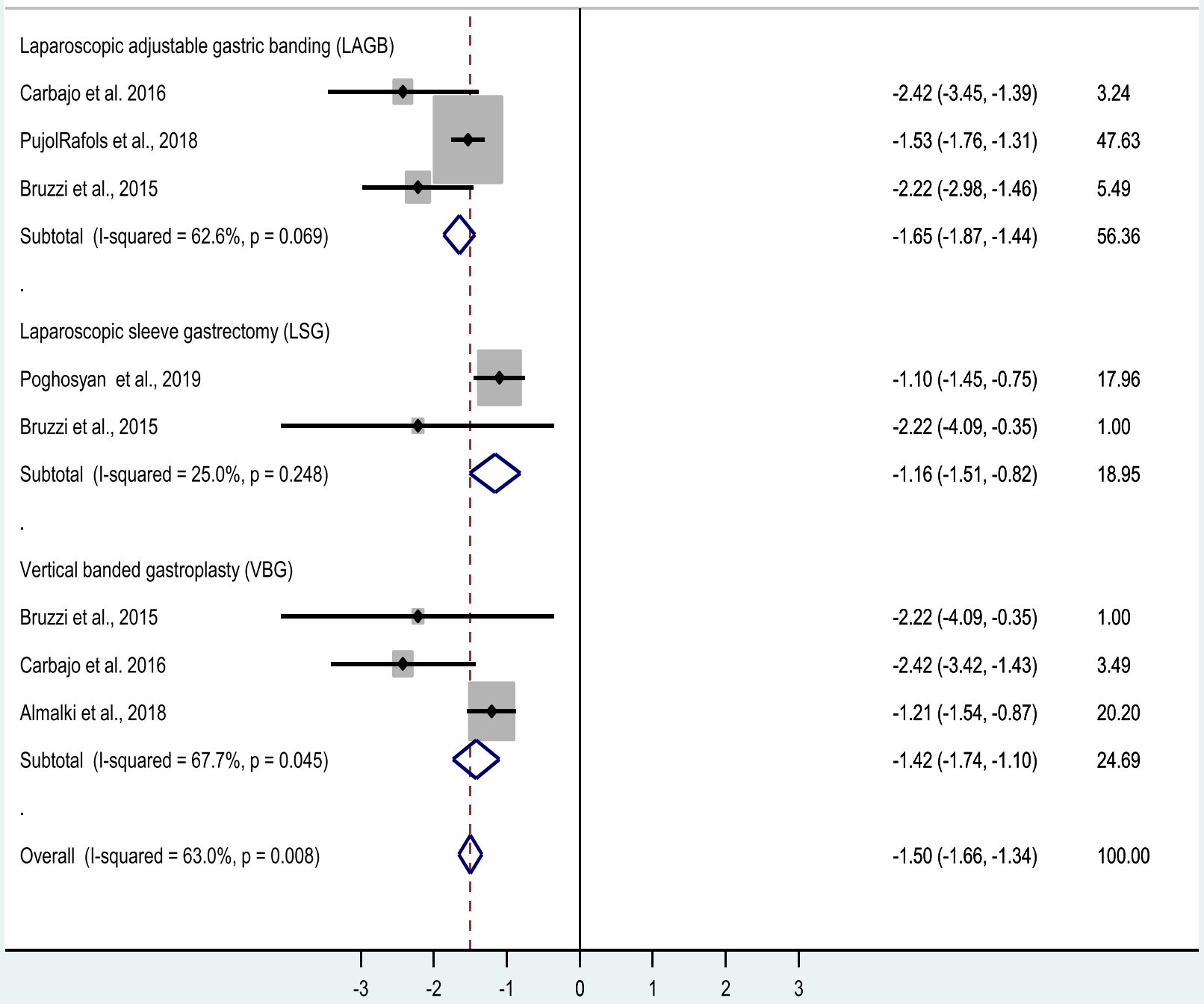

Fig. 5 Forest plot showing the effect of OAGB/MGB on BMI after 5-year follow-up

Revisional OAGB/MGB operation also causes improvements in other comorbidities, such as HTN, with remission rates of 58-94\% 5 years following the redo surgery. Chiappetta et al. concluded that a 1-year follow-up leads to a greater metabolic improvement after OAGB/MGB following failed LSG compared to RYGB [25]. In the study by Debs et al., HTN was resolved or improved in 19 out of the 23 patients $(82 \%)$ after 55 months [26]. Similarly, in another study by Jamal et al., out of 19 HTN patients, all had normalized blood pressure 1 year after OAGB/MGB, and no longer need to take any antihypertensive medications or at least decreased their medication intake [30]. Conversely, Musella et al. reported a lower rate (40\%) of remission from HTN in their series [19].

In addition to T2DM remission, this analysis found an improvement in the lipid profile. Some articles did not report the DL outcomes after OAGB/MGB as a revisional operation [17, $21,23,26,30]$. Nevertheless, a $75 \%$ remission rate of DL was reported by Bruzzi et al. [24]. Chiappetta et al. also showed a $25 \%$ and $61.5 \%$ improvement in DL after revisional RYGB and OAGB/MGB, respectively [25]. Another study revealed a $56 \%$ remission of dyslipidemia after revision of failed sleeve 
Table 7 Pre-revision, at revision, and post-revision comorbidities after OAGB/MGB

\begin{tabular}{|c|c|c|c|c|c|c|c|c|c|c|c|c|c|}
\hline \multirow[t]{3}{*}{ Author/year } & \multirow[t]{3}{*}{ Number of patients } & \multicolumn{12}{|c|}{ Post-revision comorbidities remission } \\
\hline & & \multicolumn{4}{|c|}{1 year } & \multicolumn{4}{|c|}{$\leq 3$ years } & \multicolumn{4}{|c|}{$\leq 5$ years } \\
\hline & & HTN & $\mathrm{T} 2 \mathrm{DM}$ & OSA & DL & HTN & $\mathrm{T} 2 \mathrm{DM}$ & OSA & DL & HTN & $\mathrm{T} 2 \mathrm{DM}$ & OSA & DL \\
\hline AlSabah 2018 [22] & 31 & 50 & - & - & - & - & - & - & - & - & - & - & - \\
\hline Bhandari 2019 [23] & 32 & 81.8 & 88.8 & - & - & 81.8 & 88.8 & - & - & 81.8 & 71.4 & - & - \\
\hline Chiappetta 2019 [25] & 34 & 100 & 66.7 & 80 & 61.5 & - & - & - & - & - & - & - & - \\
\hline Debs 2020 [26] & 77 & - & - & - & - & - & - & - & - & 65 & 62 & 82 & - \\
\hline Jamal 2020 [30] & 56 & 42 & 40 & - & - & - & - & - & - & - & - & - & - \\
\hline Poghosyan 2019 [27] & 72 & - & - & - & - & 21 & 75 & 70 & - & - & - & - & - \\
\hline Musella 2019 [19] & 300 & - & - & - & - & 45 & 12 & - & 11 & - & - & - & - \\
\hline Bruzzi 2016 [24] & 30 & - & - & - & - & - & - & - & & 58 & 85 & - & 75 \\
\hline Chevallier 2015 [8] & 177 & - & - & - & - & 52.1 & 85.7 & 50 & 80.6 & - & - & - & - \\
\hline Carbajo 2017 [9] & 27 & - & - & - & - & - & - & - & - & 94 & 94 & 90 & 96 \\
\hline Poublon 2020 [31] & 185 & - & - & - & - & - & 96.9 & 87.5 & 80 & - & - & - & - \\
\hline
\end{tabular}

gastrectomy or adjustable band to OAGB/MGB [19]. Lipid profile change after primary OAGB/MGB was also reported by Milone et al., and more than $50 \%$ of the patients had a normal lipid profile after primary OAGB/MGB [46].

Furthermore, an OAGB/MGB operation also caused improvements in OSA, with average remission rates of $86 \%$ in the 5-year follow-up. In the study by Debs et al., HTN was resolved in 27 out of the 33 patients (82\%) after 55 months [26]. In the study by Bruzzi et al., no significant differences were found in the remission rates of any obesity-related comorbidity such as OSA, which had occurred in the revisional and primary groups. These authors reported a 50\% remission rate for OSA in both groups [24]. Similarly, Piazza et al. found a $66 \%$ remission only 6 months after OAGB/MGB following failed adjustable GB [20].
Although there is a clear difference between acid reflux and bile reflux [47], the risk of GERD and/or bile reflux after primary and revisional OAGB/MGB is currently debated in literature $[48,49]$. Present meta-analysis showed that conversional OAGB/MGB can lead to GERD improvement in approximately $82 \%$ of patients. Only three studies reported de novo GERD and bile reflux (BR) in the patients who had no GERD symptoms before conversional OAGB/MGB [10, 26, 27]. A defective surgical technique could be the reason for reflux after conversional OAGB/MGB, especially due to a short gastric pouch $[10,50,51]$ or the presence of undetected and non-repaired hiatal hernia [52].

Redo surgery is often burdened by a higher rate of postoperative complications due to the more complicated surgery procedure; however, even though revisional OAGB/MGB
Table 8 Remission of HTN, T2DM, OSA, and DL following OAGB/MGB surgery at 1-, 3-, and 5-year follow-up

\begin{tabular}{llll}
\hline Post-revision remission rate range & Minimum (\%) & Maximum (\%) & Mean \pm Std. deviation \\
\hline HTN at 1-year follow-up & 42 & 100 & $68.5 \pm 27.2$ \\
T2DM1 at 1-year follow-up & 40 & 88.8 & $65.2 \pm 24.4$ \\
OSA at 1-year follow-up & 80 & 80.0 & $80 \pm 0$ \\
DL at 1-year follow-up & 61 & 61.5 & $61.5 \pm 0$ \\
HTN at 3-year follow-up & 21 & 81.8 & $49.9 \pm 25$ \\
T2DM at 3-year follow-up & 12 & 88.8 & $65.4 \pm 36.1$ \\
OSA at 3-year follow-up & 50 & 70.0 & $60 \pm 14.1$ \\
DL at 3-year follow-up & 11 & 80.6 & $45.8 \pm 49.2$ \\
HTN at 5-year follow-up & 58 & 94.0 & $74.7 \pm 16.3$ \\
T2DM at 5-year follow-up & 62 & 94.0 & $78.1 \pm 14.2$ \\
OSA at 5-year follow-up & 82 & 90.0 & $86 \pm 5.7$ \\
DL at 5-year follow-up & 75 & 96.00 & $85.5 \pm 14.8$
\end{tabular}


Table 9 Rate of preoperative and postoperative GERD in revisional OAGB/MGB surgery

\begin{tabular}{lllll}
\hline Author/year & $\begin{array}{l}\text { Pre-revision } \\
\text { GERD }(\%)\end{array}$ & Post-revision GERD (\%) & Remission (\%) & Remission mean \pm SD \\
\hline Noun 2007 [36] & 18.2 & 0 & 100 & $81.8 \pm 29.7$ \\
Piazza 2015 [20] & 8.3 & 0 & 100 & \\
Chiappetta 2019 [25] & 14.7 & 11.8 & 19.7 & \\
Almalki 2018 [21] & 18.5 & - & - & \\
Musella 2019 [19] & 4.6 & 2 & 56.5 & \\
Lessing 2020 [17] & 29.8 & 0 & 100 & \\
Bruzzi 2016 [24] & 13 & - & - & \\
Lessing 2017 [32] & 9.1 & 0 & 100 & \\
Carbajo 2017 [9] & 29.6 & 0 & 78 & \\
Poublon 2020 [31] & 10.2 & 2.2 & & \\
\hline
\end{tabular}

needs skilled and expert surgeons, the intervention itself appears to be more feasible than classic RYGB or other malabsorptive operations. The present review showed that complications such as port site infection, abscess, trocar site hernia, incisional hernia, colonic necrosis, bowel obstruction and ileus, pneumonia, and anastomotic stricture were within the range of primary OAGB/MGB. The first most common complication was leakage, with a rate of $1.6 \%$, which is slightly higher than for the primary procedure, and the second most common complication was bleeding, with a rate of $1.2 \%$, which was comparable to that for primary OAGB/MGB [12, $14,53-55]$. The rate of hypoalbuminemia was only $0.2 \%$ in 1771 patients although most studies report a BPL of $200 \mathrm{~cm}$. It may be under-reported as a major complication in some studies or lesser effect on albumin as a revisional procedure in patient who had an initial bariatric procedure.

\section{Strength and Limitations}

It must be considered no RCTs on OAGB/MGB as revisional surgery following restrictive procedures have been published so far. Although a similar paper has recently been published [14], this study is the first systematic review in which a metaanalysis has been developed. Also, conversion surgery data from VBG to OAGB/MGB have been evaluated. Main limitation is surely represented by the retrospective setting of all studies we considered. Again, although recalled in Table 4, it
Table 10 Major complication rate reported in included studies

\begin{tabular}{lll}
\hline Complication & Total complication in 1771 patients & Rate \% \\
\hline Leakage & 29 & 1.6 \\
Bleeding & 23 & 1.2 \\
Hematoma and abscess & 12 & 0.6 \\
GIB & 2 & 0.1 \\
Hypoalbuminaemia & 4 & 0.2 \\
Reoperation & 2 & 0.1 \\
Strangulated hernia at trocar port & 2 & 0.1 \\
Late incisional hernia & 4 & 0.2 \\
Colonic necrosis & 1 & 0.06 \\
Bowel obstruction & 3 & 0.1 \\
Respiratory failure & 1 & 0.06 \\
Stricture & 4 & 0.2 \\
Intractable bile reflux & 2 & 0.1 \\
Small bowel ileus & 2 & 0.1 \\
Pneumonia & 1 & 0.06 \\
GJ stoma fistula & 1 & 0.06 \\
Hematemesis & 1 & 0.06 \\
Port site infection & 1 & 0.06 \\
Ulceration & 4 & 0.2 \\
\hline
\end{tabular}


Table 11 Effect of gastric remnant resection on BMI following revisional $\mathrm{OAGB} / \mathrm{MGB}$ at 1 year of follow-up

\begin{tabular}{lllll}
\hline Variable & Remnant resection $(n=319)$ & Mean & $t$ & $P$ value \\
\hline Post-revision BMI $\leq 1$ year $\left(\mathrm{kg} / \mathrm{m}^{2}(\right.$ & Yes & $31.6 \pm 3.7$ & -0.19 & 0.86 \\
& No & $31.9 \pm 2.2$ & & \\
Post-revision BMI $\leq 3$ years $\left(\mathrm{kg} / \mathrm{m}^{2}\right)$ & Yes & $37.1 \pm 0$ & 1.85 & 0.12 \\
& No & $30.9 \pm 3.1$ & & \\
Post-revision $\mathrm{BMI} \leq 5$ years $\left(\mathrm{kg} / \mathrm{m}^{2}\right)$ & Yes & $28.5 \pm 0.9$ & -2.25 & 0.11 \\
& No & $32.3 \pm 2.2$ & & \\
\hline
\end{tabular}

must be noted that definition for weight regain is not univocal in many of the papers we retrieved.

\section{Conclusion}

$\mathrm{OAGB} / \mathrm{MGB}$ as a revisional procedure after failed restrictive bariatric surgery is feasible and effective. Regardless of the BPL length, conversion to OAGB/MGB induces further weight loss after LSG, VGB, and especially LAGB. The rate of remission of classic obesity-related diseases after this procedure is satisfactory, and its postoperative complications are comparable to those of primary OAGB/MGB.

Author's Contribution MK and RV conceived the original study and design. MK, RV, SSS, and AHD were responsible for data collection, data recording, and preparing the manuscript. GB and AV contributed to writing the manuscript. MM and $\mathrm{MC}$ and the rest of authors have read and approved the final manuscript.

Funding Open access funding provided by Università degli Studi di Napoli Federico II within the CRUI-CARE Agreement.

\section{Compliance with Ethical Standards}

Conflict of Interest The authors declare that they have no conflict of interest.

Ethical Approval This article does not contain any studies with human participants or animals performed by any of the authors.

Informed Consent Informed consent does not apply.

Open Access This article is licensed under a Creative Commons Attribution 4.0 International License, which permits use, sharing, adaptation, distribution and reproduction in any medium or format, as long as you give appropriate credit to the original author(s) and the source, provide a link to the Creative Commons licence, and indicate if changes were made. The images or other third party material in this article are included in the article's Creative Commons licence, unless indicated otherwise in a credit line to the material. If material is not included in the article's Creative Commons licence and your intended use is not permitted by statutory regulation or exceeds the permitted use, you will need to obtain permission directly from the copyright holder. To view a copy of this licence, visit http://creativecommons.org/licenses/by/4.0/.

\section{References}

1. Phillips BT, Shikora SA. The history of metabolic and bariatric surgery: development of standards for patient safety and efficacy. Metabolism. 2018;79:97-107.

2. Schauer PR, Bhatt DL, Kirwan JP, et al. Bariatric surgery versus intensive medical therapy for diabetes - 5-year outcomes. N Engl J Med. 2017;376(7):641-51.

3. Gloy VL, Briel M, Bhatt DL, et al. Bariatric surgery versus nonsurgical treatment for obesity: a systematic review and metaanalysis of randomised controlled trials. BMJ. 2013;347:f5934.

4. Rutledge $\mathrm{R}$. The mini-gastric bypass: experience with the first 1,274 cases. Obes Surg. 2001;11(3):276-80.

5. Carbajo M, García-Caballero M, Toledano M, et al. Oneanastomosis gastric bypass by laparoscopy: results of the first 209 patients. Obes Surg. 2005;15(3):398-404.

6. Ramos AC, Chevallier JM, Mahawar K, et al. IFSO (International federation for surgery of obesity and metabolic disorders) consensus conference statement on one-anastomosis gastric bypass (OAGBMGB): results of a modified delphi study. IFSO consensus conference contributors. Obes Surg. 2020;30(5):1625-34.

7. Mahawar KK, Himpens J, Shikora SA, et al. The first consensus statement on one anastomosis/mini gastric bypass (OAGB/MGB) using a modified Delphi approach. Obes Surg. 2018;28(2):303-12.

8. Chevallier JM, Arman GA, Guenzi M, et al. One thousand single anastomosis (omega loop) gastric bypasses to treat morbid obesity in a 7-year period: outcomes show few complications and good efficacy. Obes Surg. 2015;25(6):951-8.

9. Carbajo MA, Luque-de-León E, Jiménez JM, et al. Laparoscopic one-anastomosis gastric bypass: technique, results, and long-term follow-up in 1200 patients. Obes Surg. 2017;27(5):1153-67.

10. Musella M, Susa A, Manno E, et al. Complications following the mini/one anastomosis gastric bypass (MGB/OAGB): a multiinstitutional survey on 2678 patients with a mid-term (5 years) follow-up. Obes Surg. 2017;27(11):2956-67.

11. Alkhalifah N, Lee W-J, Hai TC, et al. 15-year experience of laparoscopic single anastomosis (mini-) gastric bypass: comparison with other bariatric procedures. Surg Endosc. 2018;32(7):3024-31.

12. Parmar CD, Bryant C, Luque-de-Leon E, et al. One anastomosis gastric bypass in morbidly obese patients with BMI $\geq 50 \mathrm{~kg} / \mathrm{m} 2$ : a systematic review comparing it with roux-en-Y gastric bypass and sleeve gastrectomy. Obes Surg. 2019;29(9):3039-46.

13. Altieri MS, Yang J, Nie L, et al. Rate of revisions or conversion after bariatric surgery over 10 years in the state of New York. Surg Obes Relat Dis. 2018;14(4):500-7.

14. Parmar CD, Gan J, Stier C, et al. One anastomosis/mini gastric bypass (OAGB-MGB) as revisional bariatric surgery after failed primary adjustable gastric band (LAGB) and sleeve gastrectomy (SG): a systematic review of 1075 patients. [published online ahead of print, 2020 Jul 29]. Int J Surg. 2020;S1743-9191(20):30542. https://doi.org/10.1016/j.ijsu.2020.07.007.

15. Hutton B, Catala-Lopez F, Moher D. The PRISMA statement extension for systematic reviews incorporating network meta- 
analysis: PRISMA-NMA. Med Clin (Barc). 2016;147(6):262-6. https://doi.org/10.1016/j.medcli.2016.02.025.

16. NIo H. Quality assessment tool for before-after (pre-post) studies with no control group [cited 02-06-2015]. 2014. Available at: http:// www.nhlbi.nih.gov/health-pro/guidelines/in-develop/ cardiovascular-risk-reduction/tools/before-after. Accessed 10 Sept 2020.

17. Lessing Y, Nevo N, Pencovich N, et al. One anastomosis gastric bypass as a revisional procedure after failed laparoscopic adjustable gastric banding. Obes Surg. 2020;30(9):3296-300. https://doi.org/ 10.1007/s11695-020-04569-2.

18. Moszkowicz D, Rau C, Guenzi M, et al. Laparoscopic omega-loop gastric bypass for the conversion of failed sleeve gastrectomy: early experience. J Visc Surg. 2013;150(6):373-8.

19. Musella M, Bruni V, Greco F, et al. Conversion from laparoscopic adjustable gastric banding (LAGB) and laparoscopic sleeve gastrectomy (LSG) to one anastomosis gastric bypass (OAGB): preliminary data from a multicenter retrospective study. Surg Obes Relat Dis. 2019;15(8):1332-9.

20. Piazza L, Di Stefano C, Ferrara F, et al. Revision of failed primary adjustable gastric banding to mini-gastric bypass: results in 48 consecutive patients. Updat Surg. 2015;67(4):433-7.

21. Almalki OM, Lee W-J, Chen J-C, et al. Revisional gastric bypass for failed restrictive procedures: comparison of single-anastomosis (mini-) and roux-en-Y gastric bypass. Obes Surg. 2018;28(4):970-5.

22. AlSabah S, Al Haddad E, Al-Subaie S, et al. Short-term results of revisional single-anastomosis gastric bypass after sleeve gastrectomy for weight regain. Obes Surg. 2018;28(8):2197-202.

23. Bhandari M, Humes T, Kosta S, et al. Revision operation to oneanastomosis gastric bypass for failed sleeve gastrectomy. Surg Obes Relat Dis. 2019;15(12):2033-7.

24. Bruzzi M, Voron T, Zinzindohoue F, et al. Revisional singleanastomosis gastric bypass for a failed restrictive procedure: 5year results. Surg Obes Relat Dis. 2016;12(2):240-5.

25. Chiappetta S, Stier C, Scheffel O, et al. Mini/one anastomosis gastric bypass versus Roux-en-Y gastric bypass as a second step procedure after sleeve gastrectomy - a retrospective cohort study. Obes Surg. 2019;29(3):819-27.

26. Debs T, Petrucciani N, Kassir R, et al. Laparoscopic conversion of sleeve gastrectomy to one anastomosis gastric bypass for weight loss failure: mid-term results. Obes Surg. 2020;30(6):2259-65. https://doi.org/10.1007/s11695-020-04461-z

27. Poghosyan T, Alameh A, Bruzzi M, et al. Conversion of sleeve gastrectomy to one anastomosis gastric bypass for weight loss failure. Obes Surg. 2019;29(8):2436-41.

28. Rafols JP, Al Abbas AI, Devriendt S, et al. Roux-en-Y gastric bypass, sleeve gastrectomy, or one anastomosis gastric bypass as rescue therapy after failed adjustable gastric banding: a multicenter comparative study. Surg Obes Relat Dis. 2018;14(11):1659-66.

29. Noun R, Slim R, Chakhtoura G, et al. Resectional one anastomosis gastric bypass/mini gastric bypass as a novel option for revision of restrictive procedures: preliminary results. J Obes. 2018;2018:1-6.

30. Jamal MH, Almutairi R, Elabd R, et al. The safety and efficacy of procedureless gastric balloon: a study examining the effect of elipse intragastric balloon safety, short and medium term effects on weight loss with 1-year follow-up post-removal. Obes Surg. 2019;29(4): 1236-41. https://doi.org/10.1007/s11695-018-03671-w.

31. Poublon N, Chidi I, Bethlehem M, et al. One anastomosis gastric bypass vs. Roux-en-Y gastric bypass, remedy for insufficient weight loss and weight regain after failed restrictive bariatric surgery. Obes Surg. 2020;30:3287-94. https://doi.org/10.1007/ s11695-020-04536-x.

32. Lessing Y, Pencovich N, Khatib M, et al. One-anastomosis gastric bypass: first 407 patients in 1 year. Obes Surg. 2017;27(10):2583-9.

33. Oliver IM, Fernández NC, Ballester RA, et al. Revisional bariatric surgery due to failure of the initial technique: 25 years of experience in a specialized unit of obesity surgery in Spain. Cir Esp (English Edition). 2019;97(10):568-74.

34. Chansaenroj P, Aung L, Lee W-J, et al. Revision procedures after failed adjustable gastric banding: comparison of efficacy and safety. Obes Surg. 2017;27(11):2861-7.

35. Ghosh S, Skinner CE, Tan S, et al. A 12-month review of revisional single anastomosis gastric bypass for complicated laparoscopic adjustable gastric banding for body mass index over 35. Obes Surg. 2017;27(11):3048-53.

36. Noun R, Zeidan S, Riachi E, et al. Mini-gastric bypass for revision of failed primary restrictive procedures: a valuable option. Obes Surg. 2007;17(5):684-8.

37. Rutledge R. Revision of failed gastric banding to mini-gastric bypass. Obes Surg. 2006;16(4):521-3.

38. Salama T, Sabry K. Redo surgery after failed open VBG: laparoscopic minigastric bypass versus laparoscopic Roux en Y gastric bypass — which is better? Minim Invasive Surg. 2016;2016:1-4.

39. Wang W, Huang M-T, Wei P-L, et al. Laparoscopic mini-gastric bypass for failed vertical banded gastroplasty. Obes Surg. 2004;14(6):777-82.

40. Noun R, Skaff J, Riachi E, et al. One thousand consecutive minigastric bypass: short-and long-term outcome. Obes Surg. 2012;22(5):697-703.

41. Vitiello A, Berardi G, Velotti N, et al. Is there an indication left for gastric band? A single center experience on 178 patients with a follow-up of 10 years. Updates Surg. 2020. https://doi.org/10. 1007/s13304-020-00858-8.

42. Lauti M, Kularatna M, Hill AG, et al. Weight regain following sleeve gastrectomy - a systematic review. Obes Surg. 2016;26(6): 1326-34.

43. Keleidari B, Mahmoudieh M, Shahabi S, et al. Reversing oneanastomosis gastric bypass surgery due to severe and refractory hypoalbuminemia. World J Surg. 2020;44(4):1200-8.

44. Mahmoudieh M, Keleidari B, Afshin N, et al. The early results of the laparoscopic mini-gastric bypass/one anastomosis gastric bypass on patients with different body mass index. J Obes. 2020;2020:1-6.

45. Ruiz-Tovar J, Carbajo MA, Jimenez JM, et al. Are there ideal small bowel limb lengths for one-anastomosis gastric bypass (OAGB) to obtain optimal weight loss and remission of comorbidities with minimal nutritional deficiencies? World J Surg. 2020;44(3):855-62.

46. Milone M, Lupoli R, Maietta $\mathrm{P}$, et al. Lipid profile changes in patients undergoing bariatric surgery: a comparative study between sleeve gastrectomy and mini-gastric bypass. Int J Surg. 2015;14:28-32.

47. Kular K, Manchanda N, Rutledge R. A 6-year experience with 1, 054 mini-gastric bypasses - first study from Indian subcontinent. Obes Surg. 2014;24(9):1430-5.

48. Musella M, Vitiello A. The eternal dilemma of the bile into the gastric pouch after OAGB: do we need to worry? Obes Surg. 2020. https://doi.org/10.1007/s11695-020-04845-1.

49. Csendes A. Bile reflux after one anastomosis gastric bypass. Obes Surg. 2020;30(7):2802-3.

50. Seetharamaiah S, Tantia O, Goyal G, et al. LSG vs OAGB - 1 year follow-up data — a randomized control trial. Obes Surg. 2017;27(4): 948-54.

51. Apers J, Wijkmans R, Totte E, et al. Implementation of mini gastric bypass in the Netherlands: early and midterm results from a highvolume unit. Surg Endosc. 2018;32(9):3949-55.

52. Kermansaravi M, Kabir A, Mousavimaleki A, et al. Association between hiatal hernia and gastroesophageal reflux symptoms after one anastomosis/mini gastric bypass (OAGB/MGB). Surg Obes Relat Dis. 2020;16:863-7.

53. Musella M, Susa A, Greco F, et al. The laparoscopic mini-gastric bypass: the Italian experience: outcomes from 974 consecutive cases in a multicenter review. Surg Endosc. 2014;28(1):156-63.

54. Georgiadou D, Sergentanis TN, Nixon A, et al. Efficacy and safety of laparoscopic mini gastric bypass. A systematic review. Surg Obes Relat Dis. 2014;10(5):984-91. 